\title{
Variability of lonospheric TEC and the Performance of the IRI-2012 Model at the BJFS Station, China
}

\author{
Shuhui LI, Lihua LI, and Junhuan PENG \\ School of Land Science and Technology, China University of Geosciences, \\ Beijing, China; e-mail: li.shuhui@163.com
}

\begin{abstract}
We studied variation characteristics of ionospheric total electron contents (TEC) and performance of the International Reference Ionosphere (IRI)-2012 model in predicting TEC at the BJFS (Beijing Fangshan station), China. Diurnal and seasonal variations were analyzed with TEC data derived from dual-frequency global positioning system (GPS) observations along with the solar activity dependence of TEC at the BJFS station. Data interpolated with information from IGS Global Ionosphere Maps (GIMs) were also used in the analysis. Results showed that the IRI-2012 model can reflect the climatic characteristics and solar activity dependence of ionospheric TEC. By using time series decomposition method, ionospheric daily averaged TEC values were divided into the periodic components, geomagnetic activity component, solar activity component and secular trend. Solar activity component and periodic components are supposed to be the main reasons which account for the difference between the GIMs TEC and the TEC from the IRI-2012 model.
\end{abstract}

Key words: ionosphere, total electron content (TEC), International Reference Ionosphere (IRI) model, time series decomposition.

\section{INTRODUCTION}

The ionosphere is a layer of the Earth's atmosphere that is ionized by solar and cosmic radiations. It can refract and reflect radio waves, thereby influ-

Ownership: Institute of Geophysics, Polish Academy of Sciences;

(C) $2016 \mathrm{Li}$ et al. This is an open access article distributed under the Creative Commons

Attribution-NonCommercial-NoDerivs license,

http://creativecommons.org/licenses/by-nc-nd/3.0/. 
encing their propagation to distant places on the Earth. It also affects the waves between satellites and the Earth. For instance, the ionospheric delay is the most important factor that affects the positioning accuracy of a global navigation satellite system (GNSS) in an application, especially for singlefrequency receivers. Hence, modelling and predicting temporal and spatial variations in ionospheric parameters are significant to ionospheric physics research and ionospheric delay correction.

To date, researchers have developed various global ionosphere models to predict ionospheric parameters. These models can be classified into three main categories: physical, parametric and empirical models (Feltens et al. 2011). They can be used to predict ionospheric parameters at a particular location and time in lieu of nearby direct observations. The single frequency ionospheric correction algorithm (SF ICA) for global positioning system (GPS) is based on the Bent model (Klobuchar 1987). SF ICA uses eight broadcast coefficients from the navigation message to compute vertical total electron content (TEC). Many further studies have been conducted on the Klobuchar model to improve the correction accuracy (Yuan et al. 2008a). Assuming that the ionosphere is thin shelled, slant TEC is then computed using an appropriate mapping function and is converted to time delay. This technique is supposed correct the ionospheric time delay by $50 \%$ root-meansquare(RMS).The NeQuick electron density model is intended for application by the European global navigation satellite system "Galileo" (Hochegger et al. 2000, Nava et al. 2008). The International Reference Ionosphere (IRI; Bilitza 2001) is one of the most popularly used models. It is developed and updated continually. Recently, the IRI model was upgraded to the IRI-2012 version (Bilitza et al. 2014, Bilitza 2015), which improves significantly on the representations of electron density, the description of electron temperature and ion composition, and bottom-side thickness.

The ionospheric TEC is an important parameter that can be used to correct ionospheric delay; hence, the performance levels of different previous versions of the IRI model with respect to predicting TEC have been investigated in various regions under different solar activity conditions (Abdu et al. 1996, Bilitza et al. 1999, 2011; Ephishov et al. 2000, Ezquer et al. 2004, Jee et al. 2005, Arikan et al. 2007, Mosert et al. 2007, Gulyaeva and Gallagher 2007, Migoya Orué et al. 2008, Aggarwal 2011, Maltseva et al. 2012, Scidá et al. 2012, Kenpankho et al. 2013, Okoh et al. 2013).

Following the release of IRI-2012 as the most recent version, its performance in predicting TEC has attracted the attention of many researchers (Zakharenkova et al. 2015). The equatorial ionization anomaly (EIA) region is a hotspot for validating studies on the IRI-2012 model. Comparison studies with GPS-derived TEC have validated the performance results of the IRI2012 model over years of varied solar activity in different EIA regions 
(Bhuyan and Hazarika 2013, Nogueira et al. 2013, Arunpold et al. 2014, Asmare et al. 2014, Adebiyi et al. 2014, Karia et al. 2015, Leong et al. 2015, Panda et al. 2015, Rabiu et al. 2014). Given the predict ability of the diurnal variation of TEC, deficiencies have varied with local time, season, and latitude.

Nonetheless, studies on TEC prediction performance of IRI models in other regions are relatively sparse. To utilize the IRI model for different applications, its level of accuracy should be verified in various regions. The model is based on ionosonde data from International Radio Consultative Committee (CCIR); therefore, regions lacking CCIR data must be validated very carefully. In China, Dai and Ma (1994) analyzed the estimations of IRI86 and IRI-90 models in the Xinxiang region. IRI generates acceptable values with respect to observations made during low solar activity. IRI-90 is generally superior to IRI-86. Moreover, International Union of Radio Science (URSI) coefficients for the F2 peak plasma frequency foF2 are better than CCIR coefficients in the calculation of TEC. The IRI models are continually updated; thus, their performance in predicting TEC must be assessed. Luo et al. (2014) studied the performance of five globally accessible ionospheric models including IRI-2012, in the low- and mid-latitude regions of China under mid-solar activity condition. All of the models perform better in mid-latitude regions than in low-latitude ones. Moreover, the IRI-2012 model agrees best with the data from the international GNSS service (IGS) global ionosphere maps (GIMs) among these models.

In the current study, TEC data from GIMs and GPS observations are used to illustrate the variation characteristics of TEC at the BJFS station (geog. lat. $39.6^{\circ} \mathrm{N}$, long. $115.9^{\circ} \mathrm{E}$, mag. lat. $29.2^{\circ} \mathrm{N}$, dip $53.2^{\circ}$ ), China. Furthermore, a statistical analysis was conducted to assess the performance of the IRI-2012 model in terms of predicting ionospheric TEC at the studied station. The capability of the model to demonstrate diurnal and monthly variations as well as solar activity dependence are discussed in detail. The TEC results in a year with high solar activity (2013) and in a year with low solar activity (2009) were also examined in this study. Using time series decomposition method, ionospheric daily averaged TEC values were divided into the periodic components, geomagnetic activity component, solar activity component and secular trend. The differences of these components between GIMs TEC data and IRI-2012 model were also compared in this study. The outcome of this paper will be helpful for improving the IRI model. And the TEC variations and their comparison with the IRI-2012 obtained over BJFS station demonstrate important features of the Chinese middle latitude region. 


\section{DATA AND METHOD}

\subsection{IRI-2012 model}

The IRI model is sponsored by the Committee on Space Research (CORPAR) and the International Union of Radio Science (URSI). It is a widely used empirical model for ionospheric predictions (Bilitza 2001, Bilitza and Reinisch 2008). IRI can be used to estimate the values of electron density, electron temperature, ion temperature, ion composition, and TEC at altitudes ranging from approximately 50 to $2000 \mathrm{~km}$ at a particular location, time, and day. The model is continually improved when new data and new techniques are available; this process has resulted in several versions of the model. The first version was released in 1978 (Rawer et al. 1978) and was followed by several steadily improved versions in 1986, 1990, and 1995, 2001, and 2006. In 2013, the most recent version of the model (IRI-2012) was released for full operation. IRI-2012 includes new models for the electron and ion densities in the region below the F-peak, a storm-time model for the auroral E-region, an improved electron temperature model that incorporates variations with solar activity, and, for the first time, a description of auroral boundaries (Bilitza 2015).

The MATLAB source code of IRI-2012, which was written by Kip Knight, was employed in this study. It was downloaded from http:// www.mathworks.com/matlabcentral/fileexchange/45612-iri-2012. The files of ig_rz.dat and apf107.dat must be updated with the ionospheric indices (IG12), sunspot number (RZ12), and the solar F10.7 index. The aforementioned indices are available at http://www.ukssdc.ac.uk/cgi-bin/wdcc1/ secure/geophysical_parameters.pl. The TEC from IRI-2012 (hereafter written as TEC-IRI) can also be calculated according to http://omniweb.gsfc. nasa.gov/vitmo/iri2012_vitmo.html.

\subsection{Data sources}

The TEC time series over the mid-latitude BJFS station of China, located in the northern hemisphere, were examined in this study. The coordinates of the BJFS station are $39.6^{\circ} \mathrm{N}$ and $115.9^{\circ} \mathrm{E}$. The local time (LT) at BJFS is equivalent to the coordinated universal time (UTC) plus eight.

The dual-frequency $\left(f_{1}=1575.42 \mathrm{MHz}, f_{2}=1227.6 \mathrm{MHz}\right)$ PS receiver facilitates the monitoring of ionospheric effect on GPS signals (Yuan and $\mathrm{Ou}$ 2001, 2002; Yuan et al. 2008b, Wen et al. 2008, Li et al. 2013, 2015). In this study, we used the method M_DCB (Jin et al. 2012) to calculate the differential code biases (DCB) of satellites and receivers. An ionospheric spherical harmonic function was utilized in the M_DCB software. The outputs were the DCB estimates of the satellites and receivers as well as the TEC ionosphere coefficients for the relative region. Carrier phase-smoothed pseudo 

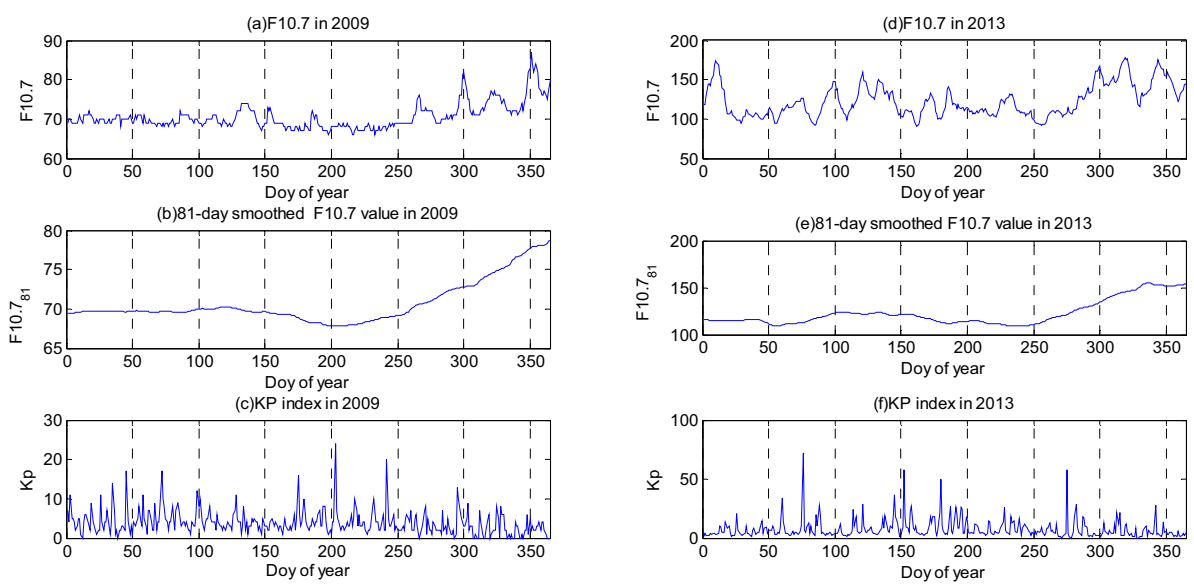

Fig. 1. Solar activity F10.7 index, its 81-day smoothed value, and geomagnetic $K p$ index in 2009 and 2013.

range $\mathrm{P} 4$ was applied in this method. Then, the slant TEC was calculated, followed by the vertical TEC (hereafter referred to as TEC-DCB) based on the observation data of GPS RINEX.

To analyze the performances of the ionospheric IRI-2012 model, we also compared the TEC-IRI data predicted by the model with the TEC values from GIMs (hereafter written as TEC-GIM) during a year with high solar activity (2013) and a year with low solar activity (2009). GIMs are downloaded from ftp://cddisa.gsfc.nasa.gov/pub/gps/products/ionex/. Xiang et al. (2015) assessed four different global ionospheric maps (GIMs) over the area of China based on internal consistency and external accuracy. They concluded that each analysis center can reproduce reliably a spatial and temporal variation of TEC.

The F10.7 indices of solar activity and its 81-day smoothed values are used in this study. The data are obtained from http://www.swpc.noaa.gov/ Data/index.html. Furthermore, the geomagnetic $K p$ index was used to measure the general level of geomagnetic activity. A geomagnetic day is considered quiet when the $K p$ index satisfies the following condition: $0=<K p$ <3.0. $K p$ index data are available at http://www.ngdc.noaa.gov/stp/ GEOMAG/kp_ap.html. Figure 1 presents the solar activity indices and geomagnetic $K p$ index in high solar activity year (2009) and low solar activity year (2013), respectively.

We computed the monthly daily variation in TEC by averaging all of the data obtained during quiet geomagnetic activity days for every moment. Months in a year are divided into four seasons: the March equinox (February, March, and April), the June solstice (May, June, and July), the Septem- 
ber equinox (August, September, and October), and the December solstice (November, December, and January).

\subsection{Time series decomposition of daily averaged TEC}

In order to examine the differences between the TEC-IRI and TEC- GIM in detail, time series analysis was carried out in our research. Following Li et al. (2013), the ionospheric daily averaged TEC time series model can be expressed as

$$
T E C(d)=T E C_{\text {period }}(d)+T E C_{\text {solar }}(d)+T E C_{\text {geomagnatic }}(d)+T E C_{\text {trend }}(d)+T E C_{0}
$$

where $T E C(d)$ is the ionospheric daily averaged TEC value and $d$ specifies its number, $T E C_{\text {period }}(d)$ is the periodic component, $T E C_{\text {solar }}(d)$ is the solar activity component, $T E C_{\text {trend }}(d)$ is the secular trend, and $T E C_{0}$ is a constant. If $M$ main cycles exist in daily averaged TEC, the periodic component can be written as:

$$
\begin{aligned}
T E C_{\text {period }}(d) & =\sum_{i=1}^{M}\left[a_{i} \cdot \sin \left(2 \pi d / T_{i}\right)+b_{i} \cdot \cos \left(2 \pi d / T_{i}\right)\right]+ \\
& +\sum_{i=1}^{M}\left[c_{i} \cdot \operatorname{in}\left(2 \pi d / T_{i}\right)+d_{i} \cdot \cos \left(2 \pi d / T_{i}\right)\right] \cdot F_{10.7 \_81}(d)
\end{aligned}
$$

where $a_{\mathrm{i}}, b_{\mathrm{i}}, c_{\mathrm{i}}$, and $d_{\mathrm{i}}$ are all coefficients. The number of coefficients of the periodic component is $4 \mathrm{M}$. Equation 2 illustrates that the comprehensive influence of periodic variation and solar activity was considered in the model. The main cycles that were included in the model are annual cycle $(365.25$ days), semiannual, $1 / 3$ years and $1 / 4$ years. With the previous day's solar F10.7 index and its 81-day smoothed value $F_{10.781}$, the solar activity component is written as:

$$
T E C_{\text {solar }}(d)=f_{1} \cdot F_{10.7}(d-1)+f_{2} \cdot F_{10.7 \_81}(d-1)
$$

where $f_{1}$ and $f_{2}$ are coefficients. The geomagnetic activity component of the daily averaged TEC time series is written as:

$$
T E C_{\text {geomanetic }}(d)=f_{3} \cdot K p(d-1)+f_{4} \cdot K p(d-2)+f_{5} \cdot K p(d-3)
$$

where $K p(d-1), K p(d-2)$, and $K p(d-3)$ are the geomagnetic $K p$ indices a day, two days, and three days before, respectively, and $f_{3}, f_{4}$, and $f_{5}$ are coefficients. The secular trend part of the model is written as

$$
T E C_{\text {trend }}(d)=f_{6} \cdot d
$$


where $f_{6}$ is the coefficient of the linear trend. Based on the daily averaged TEC values, the model parameters can be calculated by least squares method.

\section{RESULTS AND DISCUSSION}

\subsection{Diurnal variations in ionospheric TEC at BJFS}

The diurnal variation in TEC is attributed to the daily rotation of the Earth. TEC data are obtained on randomly selected quiet days of each month to determine the diurnal variations in TEC. The results for a year with low solar activity year (2009) are shown in Fig. 2, whereas those for a year with high solar activity (2013) are depicted in Fig. 3.The differences among TECDCB, TEC-GIM, and TEC-IRI are clearly presented in these figures.

During both years, the values of TEC-GIM agreed with those of TECDCB on all of the days examined. The two methods are based on dualfrequency GPS observations. However, the TEC-GIM data were relatively smooth, whereas the TEC-DCB values varied more significant in a short time. These results may be attributed to the different models used: the TECDCB derived from one IGS station (BJFS), whereas the TEC-GIM was obtained from multiple global IGS stations.

TEC was gradually increasing in the period of 04:00 to 06:00 $\mathrm{h} \mathrm{LT}$ in all months and was maximized during 12:00 to 16:00 h LT. TEC increased earlier during the June solstice than in other seasons. Furthermore, the duration for which TEC value remained high was much longer in this period than
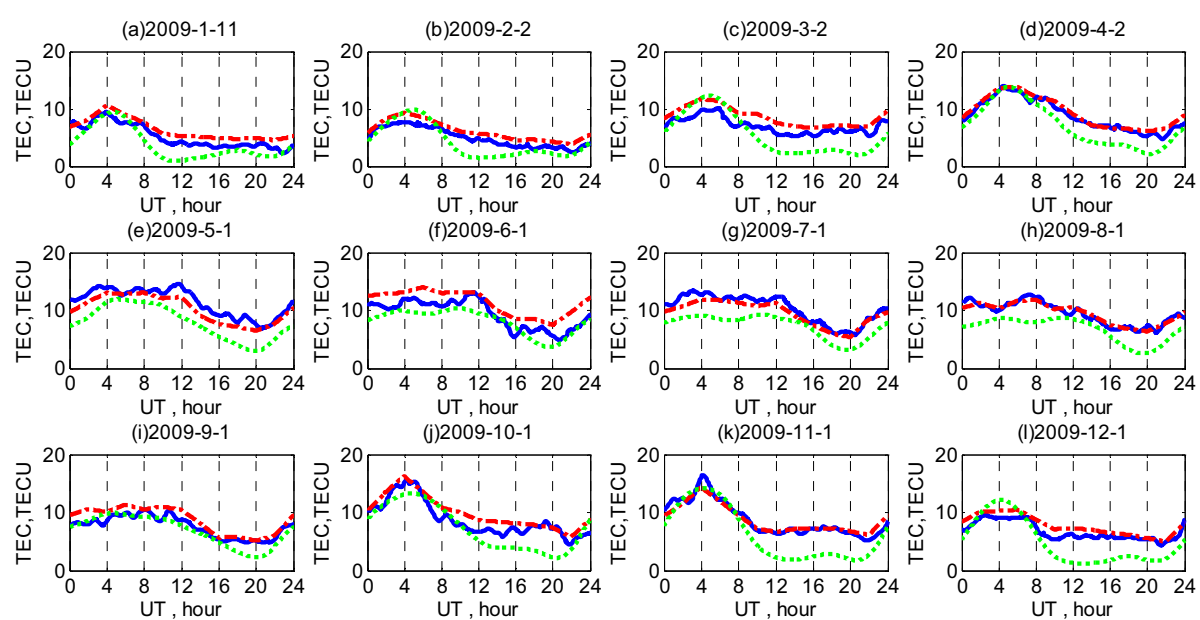

- TEC-DCB $=-$ TEC-GIM $\cdots \cdots \cdot$ TEC-IRI

Fig. 2. Diurnal variations in TEC at the BJFS station in 2009. The times are indicated in UT, which is eight hours behind the LT, i.e., LT $=\mathrm{UT}+$ 08:00 $\mathrm{h}$ at BJFS. 

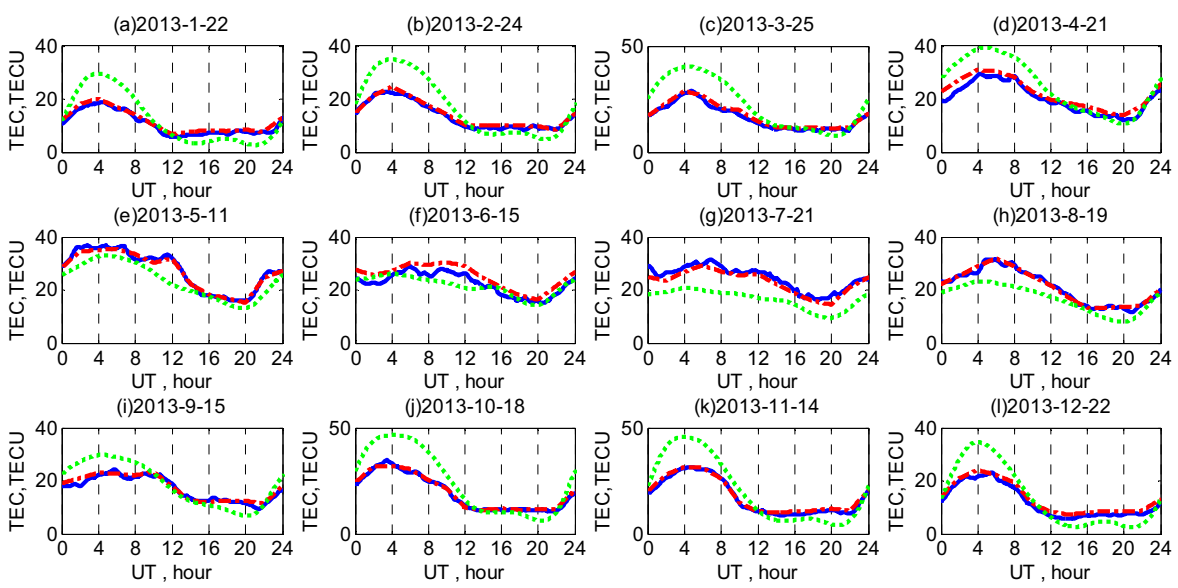

Fig. 3. Diurnal variations in TEC at the BJFS station in 2013. The times are indicated in UT, which is eight hours behind the LT, i.e., LT $=\mathrm{UT}+$ 08:00 $\mathrm{h}$ at BJFS.

in others. In addition, this high TEC value fluctuated more frequently in this time interval. The duration for which TEC values were low was generally also much longer during the other seasons than during the June solstice.

Figures 2 and 3 indicate that the value of the diurnal peak is higher during the equinoxes than during the solstice seasons. In 2009, the highest TEC value (16.4 TECU) was obtained in November of the quiet geomagnetic days examined. In 2013, the highest TEC value (37.0 TECU) was detected in May of the studied quiet geomagnetic days.

The lowest TEC values in all months were underestimated by the IRI2012 model. Moreover, the TEC values throughout the day were underestimated during June solstice seasons in 2009 and 2013.

\subsection{Monthly variations in ionosphere TEC}

Figure 4 shows the monthly averaged TEC values as obtained by different models at the BJFS station in 2009 and 2013. The values are averaged with all of the TEC data gathered during the quiet geomagnetic days of each month.

In both years, the monthly averaged TEC time series displayed two peaks, in May and October. The monthly averaged TEC in May was larger than that in October, and the value was minimal in January.

The average diurnal variations for each month in 2009 and in 2013 are depicted in Figs. 5 and 6, respectively. As with Fig. 4, the TEC data of a certain moment on quiet geomagnetic days were used to calculate the average value. 

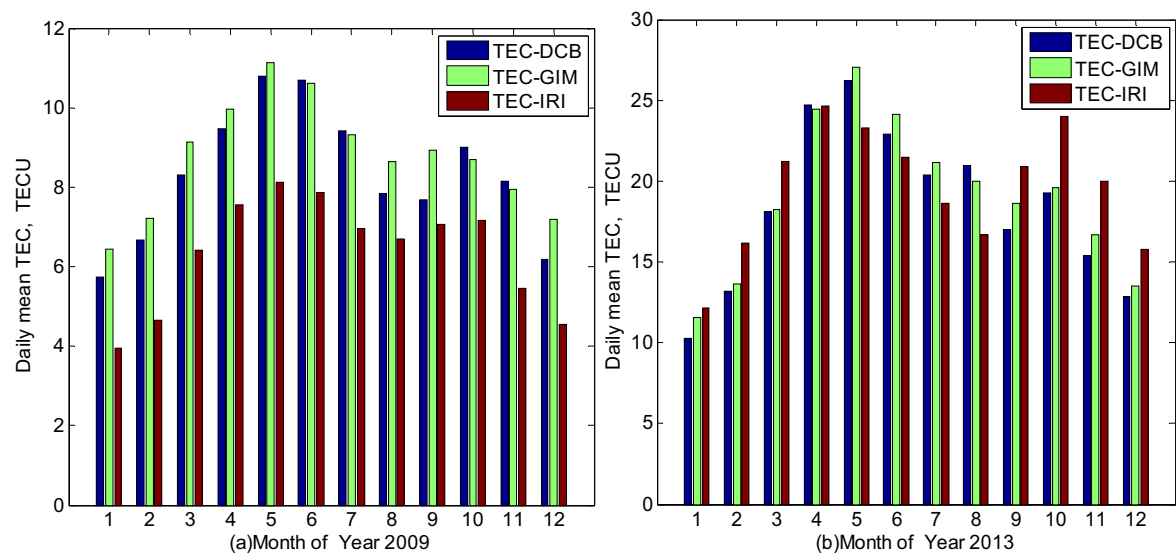

Fig. 4. Monthly averaged values in TEC at the BJFS station in (a) 2009, and (b) 2013 .

The duration for which the TEC level was high during the day was longer during the June solstice than in others, even in August. Furthermore, daytime peak values fluctuated more significantly during this period. The IRI2012 model can represent this characteristic of TEC variation effectively.

Figures 5 and 6 indicate that the minimum values of TEC at night were underestimated approximately 2 to 6 TECU in 2009 and 2013. However, daytime high level TEC was overestimation all months except during the June solstice. Thus, the TEC values for entire days were underestimated during this period. The differences in TEC at daytime and at nighttime were enhanced by TEC-IRI in other months.

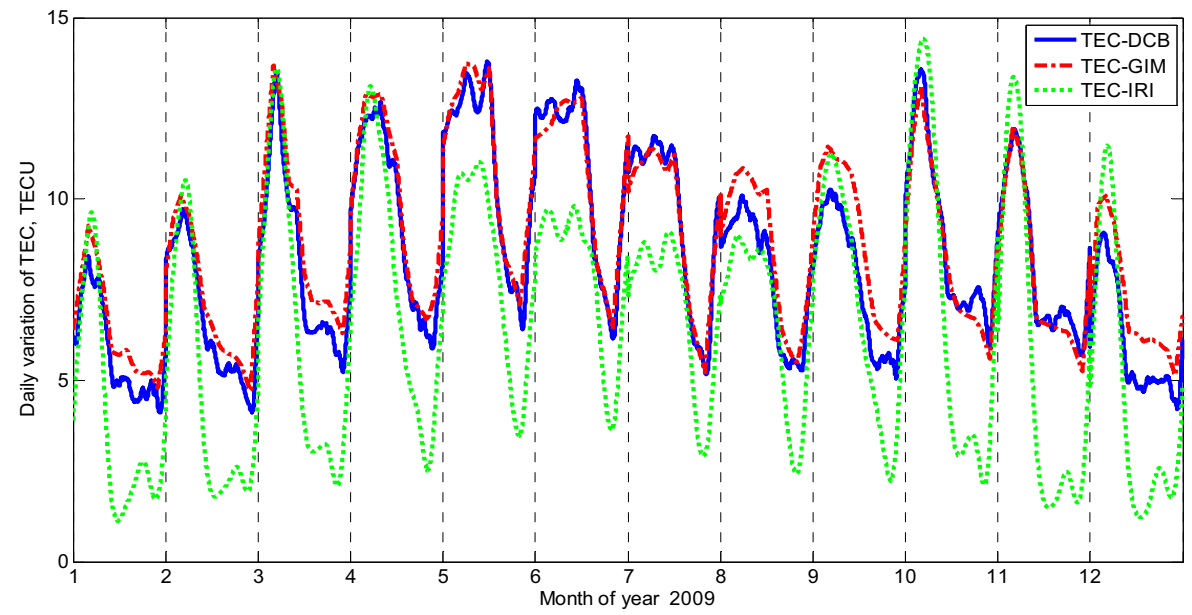

Fig. 5. The average TEC diurnal variations for different months in 2009. 


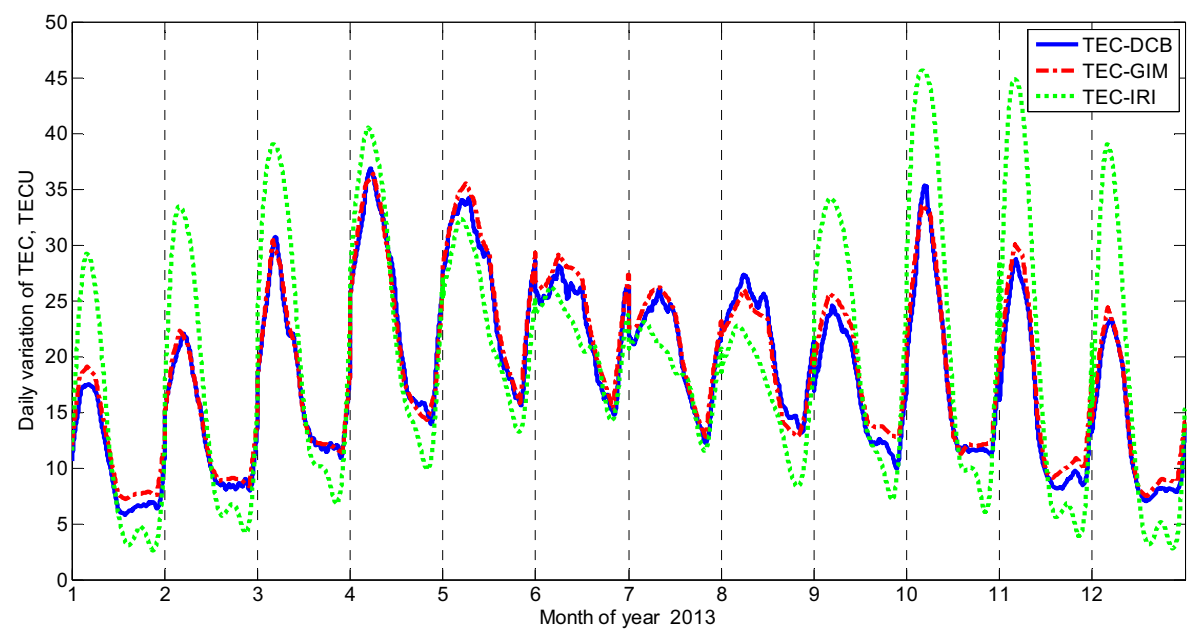

Fig. 6. The average TEC diurnal variations for different months in 2013.

The reason why the IRI-2012 model underestimates the nighttime TEC should be the contribution from the plasmasphere which cannot be represented by IRI-2012 model alone. The contribution during the daytime is relatively small but it can reach $30-40 \%$ during nighttime. So the TEC-IRI will be smaller than the TEC-GIM because of the missing plasmaspheric content. Moreover, according to the investigation of Lee et al. (2013), the relative plasmaspheric contribution to the nighttime ionosphere (via downward plasmaspheric flux) mostly decreases with increasing solar activity. Therefore, there is required a reliable and standard ionosphere-plasmasphere model (Gulyaeva and Bilitza 2012).

\subsection{Time series analysis of daily averaged TEC}

Figure 7 shows the periodic components of daily averaged TEC from GIM and IRI-2012 model in 2009. As shown in Fig. 7, the annual component presents the shape of the sine function. The annual component has maximum amplitude, and then semi-annual component, 1/3 year component and 1/4 years component. But, in general, the results of periodic components of the two kinds of data, i.e., TEC-GIM and TEC-IRI, are very close.

Figure 8 shows the impacts of different components on daily averaged TEC from GIM and IRI 2012 model in 2009. Periodic components from both, TEC-IRI and TEC-GIM, can reflect two TEC peaks during this year, and the peaks are May and October, respectively. This characteristic is in full agreement with that of monthly averaged TEC time series. However, the 

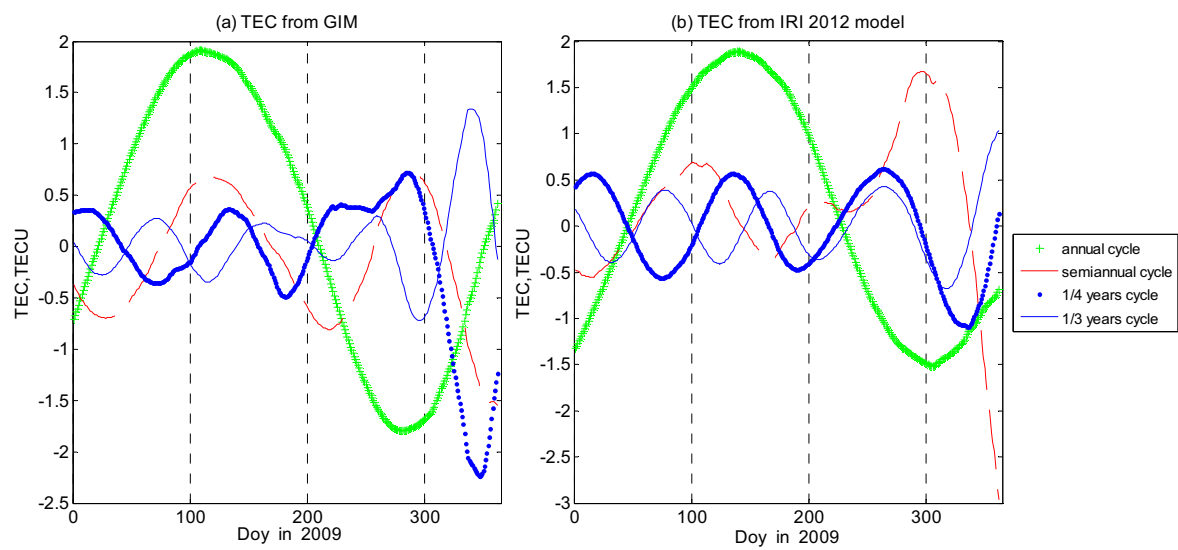

Fig. 7. Impacts of periodic components on daily averaged TEC in 2009: (a) GIMTEC, and (b) IRI-TEC.

geomagnetic activity component and solar activity component from TEC-IRI are much smaller than those of TEC-GIM obviously.

Figure 9 presents the impacts of periodic variations on daily averaged TEC values from GIMs and IRI-2012 model in a high solar activity year (2013). The results show that there exists great difference between daily averaged TEC of two years. In 2013, the annual component of TEC-GIM and TEC-IRI both present a shape of cosine function. Besides, the consistency of periodic variations between TEC-GIM and TEC-IRI is not as good as that in the low activity year (2009). The semi-annual component and $1 / 4$ year component of TEC-GIM behave in accordance with those of TEC-IRI, while there are relatively large differences in the annual period and $1 / 3$ year period
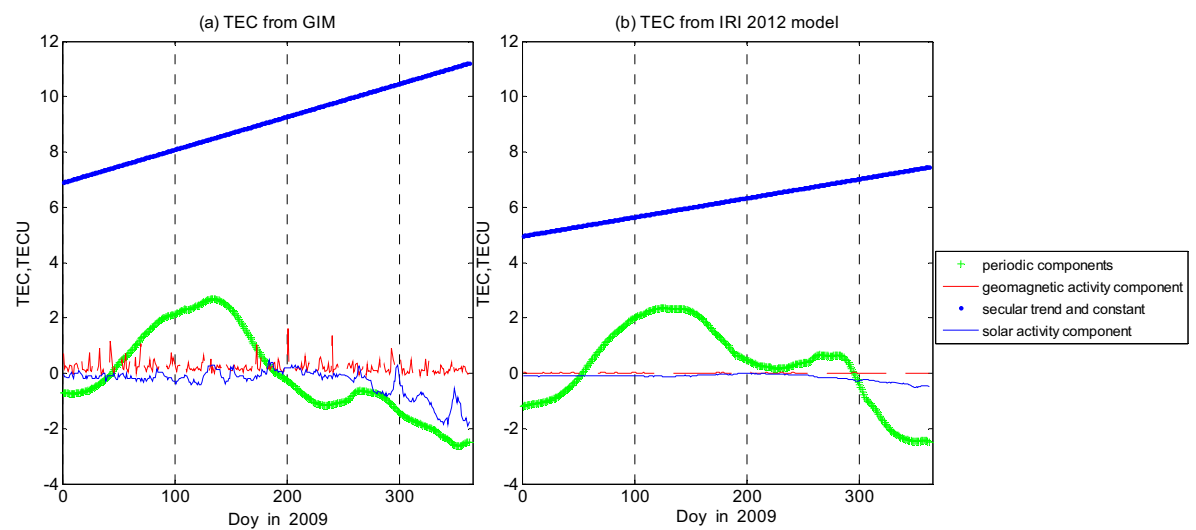

Fig. 8. Impacts of different components on daily averaged TEC in 2009: (a) TECGIM, and (b) TEC-IRI. 

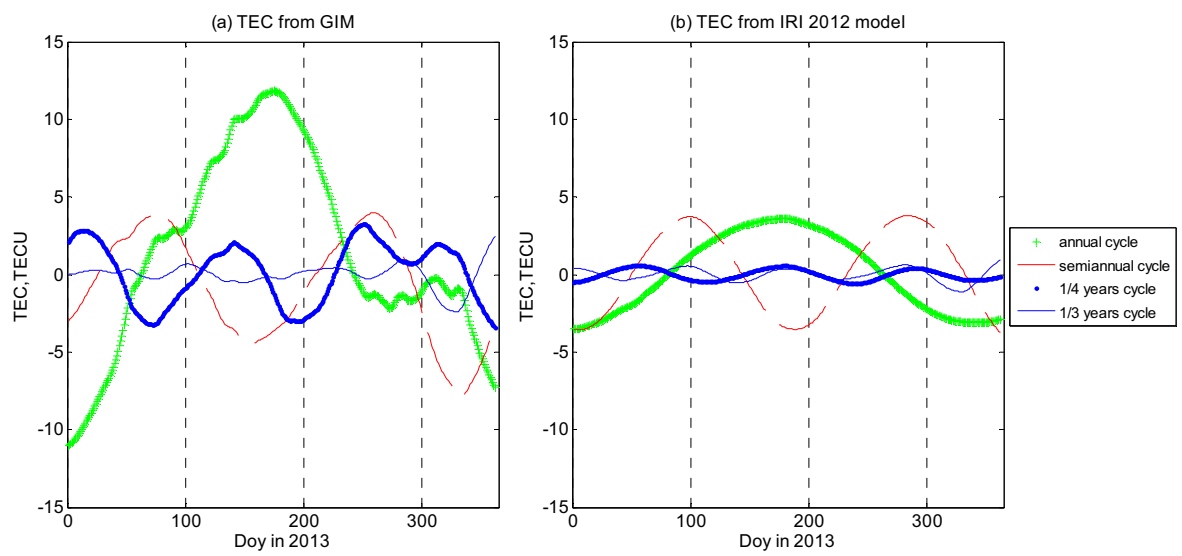

Fig. 9. Impacts of periodic components on daily averaged TEC in 2013: (a) GIMTEC, and (b) IRI-TEC.

between TEC-IRI and TEC-GIM. The magnitudes of annual component and $1 / 3$ year component are relatively low during this high solar activity year.

Figure 10 shows the impacts of different components on the daily averaged TEC-GIM and TEC-IRI in 2013. It is obvious that the results of TECGIM and TEC-IRI are significantly different. Solar activity component of TEC-GIM varied from 0 to 18 TECU, while this component of TEC-IRI varied from 0 to 2 TECU. From Figs. $4 \mathrm{~b}$ and 6, the TEC-IRI values are much larger than TEC-GIM at the beginning and the end of year 2013, while TECIRI values from May to August are much less than that of TEC-GIM. The results are similar to the difference in period variations of TEC between
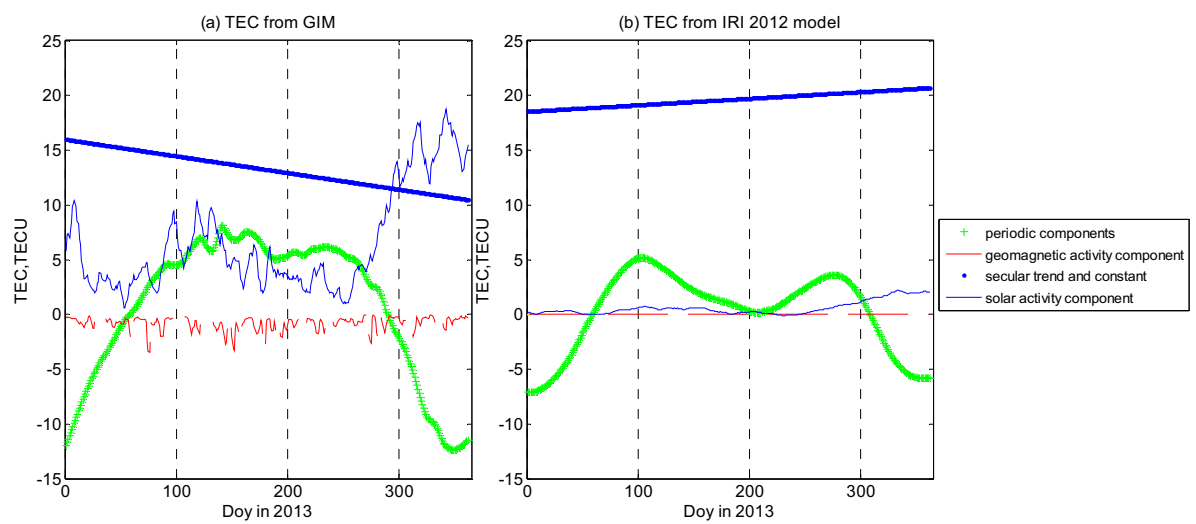

Fig. 10. Impacts of different components on daily averaged TEC in 2013: (a) TECGIM, and (b) TEC-IRI. 
TEC-IRI and TEC-GIM. According to Li et al. (2013), dependence on solar activity and periodical variation should be the main factors that dominate TEC variations. Furthermore, the influence of the annual period is more significant than that of the semi-annual period in a mid-latitude area. We can conclude that the difference between TEC-GIM and TEC-IRI is mainly due to periodic components and solar activity component.

\section{CONCLUSION}

In this study, we calculated the ionospheric TEC at the mid-latitude BJFS station in the northern hemisphere according to GPS observations in a year with high solar activity (2013) and in a year with low solar activity (2009). Then, we analyzed the diurnal variation, monthly variation, and solar dependence of the TEC time series. The main results are as follows:

1) TEC value generally increased in the period of 04:00 to $06: 00 \mathrm{~h} \mathrm{LT}$ in all seasons and was maximized in the period of 12:00 to16:00 h LT. This value increased earlier during the June solstice.

2) The duration for which the TEC value remained high was long during the June solstice. The fluctuations in TEC were frequent during this time interval.

3) The local maximum value of monthly averaged TEC was obtained May and in October, whereas the minimum value was detected in January. These results may be attributed to the comprehensive influence of solar activity, annual variation, and semi-annual variation.

The performance of the IRI -2012 models in predicting TEC values was examined by comparing the TEC-IRI with TEC-GIM. The following observations were made:

1) The IRI-2012 model underestimated nighttime TEC over both years.

2) The duration and fluctuation of daytime peak values were closely correlated with season. The IRI-2012 model could capture this characteristic of TEC variation effectively.

3) From the results of time series decomposition, periodic components of TEC-IRI in low solar activity year (2009) exhibit good agreement with that of TEC-GIM. However, their solar activity components are obviously different. But the solar activity is low, and hence TEC-IRI time series are very close to TEC-GIM.

4) In high solar activity year (2013), the differences between TEC-GIM and TEC-IRI are mainly due to periodic components and the solar activity component. For TEC-IRI, the magnitudes of annual component, 1/3 year component and solar activity component are significantly low in 2013. 
Acknowledgments. This work is supported by the Fundamental Research Funds for the Central Universities (Grant Nos. 35832015084 and 35832015083 ) and the National Natural Science Foundation of China (Grant Nos. 41104025, 41574011, and 41401622).

\section{References}

Abdu, M.A., I.S. Batista, and J.R. de Souza (1996), An over view of IRIobservational data comparison in American (Brazilian) sector low latitude ionosphere, Adv. Space Res. 18, 6, 13-22, DOI: 10.1016/02731177(95)00893-4.

Adebiyi, S.J., O.O. Odeyemi, I.A. Adimula, O.A. Oladipo, S.O. Ikubanni, B.O. Adebesin, and B.W. Joshua (2014), GPS derived TEC and foF2 variability at an equatorial station and the performance of IRI-model, $J . A d v$. Space Res. 54, 4, 565-575, DOI: 10.1016/j.asr.2014.03.026.

Aggarwal, M. (2011), TEC variability near northern EIA crest and comparison with IRI model, Adv. Space Res. 48, 7, 1221-1231, DOI: 10.1016/j.asr.2011. 05.037 .

Arikan, F., O. Arikan, and C.B. Erol (2007), Regularized estimation of TEC from GPS data for certain mid latitude stations and comparison with the IRI model, Adv. Space Res. 39, 5, 867-874, DOI: 10.1016/j.asr.2007.01.082.

Arunpold, S., N. Tripathi, R. Chowdhary, V.R. Chowdhary, and D.K. Raju (2014), Comparison of GPS-TEC measurements with IRI-2007 and IRI-2012 modeled TEC at an equatorial latitude station, Bangkok, Thailand, J. Atmos. Sol. Terr. Phys. 117, 88-94, DOI: 10.1016/j.jastp.2014.06.001.

Asmare, Y., T. Kassa, and M. Nigussie (2014), Validation of IRI-2012 TEC model over Ethiopia during solar minimum (2009) and solar maximum (2013) phases, Adv. Space Res. 53, 11, 1582-1594, DOI: 10.1016/j.asr.2014.02. 017.

Bhuyan, P.K., and R. Hazarika (2013), GPS TEC near the crest of the EIA at 95E during the ascending half of solar cycle 24 and comparison with IRI simulations, Adv. Space Res. 52, 7, 1247-1260, DOI: 10.1016/j.asr.2013.06.029.

Bilitza, D., M. Hernandez-Pajares, J.M. Juan, and J. Sanz (1999), Comparision between IRI and GPS-IGS derived electron content during 1991-97, Phys. Chem. Earth 24, 4, 311-319, DOI: 10.1016/S1464-1917(99)00004-5.

Bilitza, D. (2001), International Reference Ionosphere 2000, Radio Sci. 36, 2, 261275, DOI: $10.1029 / 2000 R S 002432$.

Bilitza, D., and B.W. Reinisch (2008), International Reference Ionosphere2007: Improvements and new parameters, Adv. Space Res. 42, 4, 599-609, DOI: 10.1016/j.asr.2007.07.048. 
Bilitza, D., L.A. McKinnell, B. Reinisch, and T. Fuller-Rowell (2011), The international reference ionosphere today and in the future, J. Geodesy 85, 12, 909920, DOI: 10.1007/s00190-010-0427-x.

Bilitza, D., D. Altadill, Y. Zhang, C. Mertens, V. Truhlik, P. Richards, L.A. McKinnell, and B. Reinisch (2014), The International Reference Ionosphere 2012 - a model of international collaboration, J. Space Weather Space Clim. 4, A07, 1-12, DOI: $10.1051 / \mathrm{swsc} / 2014004$.

Bilitza, D. (2015), The International Reference Ionosphere - Status 2013, Adv. Space Res. 55, 8, 1914-1927, DOI: 10.1016/j.asr.2014.07.032.

Dai, K., and J. Ma (1994), Comparison of total electron content calculated using the IRI with observations in China, J. Atmos. Sol. Terr. Phys. 56, 3, 417-422, DOI: 10.1016/0021-9169(94)90222-4.

Ephishov, I.I., L.W. Baran, I.I. Shagimuratov, and G.A. Yakimova (2000), Comparison of total electron content obtained from GPS with IRI, Phys. Chem. Earth 25, 4, 339-342, DOI: 10.1016/S1464-1917(00)00028-3.

Ezquer, R., C. Brunini, M. Mosert, A. Meza, R. del V. Oviedo, E. Kiorcheff, and S.M. Radicella (2004), GPS-VTEC measurements and IRI predictions in the South American sector, Adv. Space Res. 34, 9, 2035-2043, DOI: 10.1016/j.asr.2004.03.015.

Feltens, J., M. Angling, N. Jackson-Booth, N. Jakowski, M. Hoque, M. HernándezPajares, Á. Aragón, Á. María, and R. Orús-Pérez (2011), Comparative testing of four ionospheric models driven with GPS measurements, Radio Sci. 46, 6, RS0D12, DOI: 10.1029/2010RS004584.

Gulyaeva, T.L., and D.L. Gallagher (2007), Comparison of two IRI electron-density plasmasphere extensions with GPS-TEC observations, Adv. Space Res. 39, 5, 744-749, DOI: 10.1016/j.asr.2007.01.064.

Gulyaeva, T.L., and D. Bilitza (2012), Towards ISO standard Earth ionosphere and plasmasphere model. In: New Developments in the Standard Model, NOVA Publishers, https://www.novapublishers. com/catalog/product_info.php? products_id=35812.

Hochegger, G., B. Nava, S.M. Radicella, and R. Leitinger (2000), A family of ionospheric models for different uses, Phys. Chem. Earth 25, 4, 307-310, DOI: 10.1016/S1464-1917(00)00022-2.

Jee, G., R.W. Schunk, and L. Scherliess (2005), Comparison of IRI-2001 with TOPEX TEC measurements, J. Atmos. Sol. Terr. Phys. 67, 4, 365-380, DOI: 10.1016/j.jastp.2004.08.005.

Jin, R., S. Jin, and G. Feng (2012), M_DCB: Matlab code for estimating GNSS satellite and receiver differential code biases, GPS Solut. 16, 4, 541-548, DOI: 10.1007/s10291-012-0279-3.

Karia, S.P., N.C. Patel, and K.N. Pathak (2015), Comparison of GPS based TEC measurements with the IRI-2012 Model for the period of low to moderate solar activity (2009-2012) at the crest of equatorial anomaly in Indian region, Adv. Space Res.55, 8, 1965-1975, DOI: 10.1016/j.asr.2014.10.026. 
Kenpankho, P., P. Supnithi, and T. Nagatsuma (2013), Comparison of observed TEC values with IRI-2007 TEC and IRI-2007TEC with optional foF2 measurements predictions at an equatorial region, Chumphon, Thailand, Adv. Space Res. 52, 10, 1820-1826, DOI: 10.1016/j.asr.2013.08.012.

Klobuchar, J.A. (1987), Ionospheric Time-Delay Algorithm for Single-Frequency GPS users, IEEE Trans. Aerosp. Electron. Syst. 23, 3, 324-331, DOI: 10.1109/TAES.1987.310829.

Lee, H.B., G. Jee, Y.H. Kim, and J.S. Shim (2013), Characteristics of global plasmaspheric TEC in comparison with the ionosphere simultaneously observed by Jason-1 satellite, J. Geophys. Res. 118, 2, 935-946, DOI: 10.1002/jgra. 50130.

Leong, S.K., T.A. Musa, K. Omar, M.D. Subari, N.B. Pathy, and M.F. Asilam (2015), Assessment of ionosphere models at Banting: Performance of IRI2007, IRI-2012 and Ne-Quick 2 models during the ascending phase of Solar Cycle 24, J. Adv. Space Res. 55, 8, 1928-1940, DOI: 10.1016/j.asr.2014. 01.026.

Li, H., Y. Yuan, Z. Li, X. Huo, and W. Yan (2012), Ionospheric electron concentration imaging using combination of LEO satellite data with ground-based GPS observations over China, IEEE Trans. Geosci. Remote Sens. 50, 5, 1728-1735, DOI: 10.1109/TGRS.2011.2168964.

Li, S., J. Peng, W. Xu, and K. Qin (2013), Time series modeling and analysis of trends of daily averaged ionospheric total electron content, Adv. Space Res. 52, 5, 801-809, DOI: 10.1016/j.asr.2013.05.032.

Li, Z., Y. Yuan, N. Wang, M. Hernandez-Pajares, and X. Huo (2015), SHPTS: towards a new method for generating precise global ionospheric TEC map based on spherical harmonic and generalized trigonometric series functions, J. Geodesy 89, 4, 331-345, DOI: 10.1007/s00190-014-0778-9.

Luo, W., Z. Liu, and M. Li (2014), A preliminary evaluation of the performance of multiple ionospheric models in low- and mid-latitude regions of China in 2010-2011, GPS Solut. 18, 2, 297-308, DOI: 10.1007/s10291-013-0330-z.

Maltseva, O.A., N.S. Mozhaeva, O.S. Poltavsky, and G.A. Zhbankov (2012), Use of TEC global maps and the IRI model to study ionospheric response to geomagnetic disturbances, Adv. Space Res. 49, 6, 1076-1087, DOI: 10.1016/ j.asr.2012.01.005.

Migoya Orué, Y.O., S.M. Radicella, P. Coïsson, R.G. Ezquer, and B. Nava (2008), Comparing TOPEX TEC measurements with IRI predictions, Adv. Space Res. 42, 4, 757-762, DOI: 10.1016/j.asr.2007.09.041.

Mosert, M., M. Gende, C. Brunini, R. Ezquer, and D. Altadill (2007), Comparisons of IRI TEC predictions with GPS and digisonde measurements at Ebro, Adv. Space Res.39, 5, 841-847, DOI: 10.1016/j.asr.2006.10.020.

Nava, B., P. Coïsson, and S.M. Radicella (2008), A new version of the NeQuick ionosphere electron density model, J. Atmos. Sol. Terr. Phys. 70, 15, 18561862, DOI: $10.1016 /$ j.jastp.2008.01.015. 
Nogueira, P.A.B., M.A. Abdu, J.R. Souza, I.S. Batista, and G.J. Bailey (2013), Equatorial ionization anomaly development as studied by GPS TEC and foF2 over Brazil: A comparison of observations with model results from SUPIM and IRI-2012, J. Atmos. Sol. Terr. Phys. 104, 45-54, DOI: 10.1016/j.jastp. 2013.08.013.

Okoh, D., L. McKinnell, P. Cilliers, and P. Okeke (2013), Using GPS-TEC data to calibrate VTEC computed with the IRI model over Nigeria, Adv. Space Res. 52, 10, 1791-1797, DOI: 10.1016/j.asr.2012.11.013.

Panda, S.K., S.S. Gedam, and G. Rajaram (2015), Study of Ionospheric TEC from GPS observations and comparisons with IRI and SPIM model predictions in the low latitude anomaly Indian sub continental region, J. Adv. Space Res. 55, 8, 1948-1964, DOI: 10.1016/j.asr.2014.09.004.

Rabiu, A.B., A.O. Adewale, R.B. Abdulrahim, and E.O. Oyeyemi (2014), TEC derived from some GPS stations in Nigeria and comparison with the IRI and NeQuick models, J. Adv. Space Res. 53, 9, 1290-1303, DOI: 10.1016/j.asr. 2014.02.009.

Rawer, K., D. Bilitza, and S. Ramakrishnan (1978), International Reference Ionosphere 1978, International Union of Radio Science (URSI), Brussels, Belgium.

Scidá, L.A., R.G. Ezquer, M.A. Cabrera, M. Mosert, C. Brunini, and D. Buresova (2012), On the IRI 2007 performance as a TEC predictor for the South American sector, J. Atmos. Sol. Terr. Phys. 81-82, 50-58, DOI: 10.1016/ j.jastp.2012.04.001.

Wen, D., Y. Yuan, J. Ou, K. Zhang, and K. Liu (2008), A hybrid reconstruction algorithm for 3-d ionospheric tomography, IEEE Trans. Geosci. Remote Sens. 46, 6, 1733-1739, DOI: 10.1109/TGRS.2008.916466.

Xiang, Y., Y. Yuan, Z. Li, and N. Wang (2015), Analysis and validation of different global ionospheric maps (GIMs) over China, J. Adv. Space Res. 55, 1, 199210, DOI: 10.1016/j.asr.2014.09.008.

Yuan, Y., and J. Ou (2001), Auto-covariance estimation of variable samples (ACEVS) and its application for monitoring random ionospheric disturbances using GPS, J. Geodesy 75, 7-8, 438-447, DOI: 10.1007/ s001900100197.

Yuan, Y., and J. Ou (2002), Differential areas for differential stations (DADS): a new method of establishing grid ionospheric model, Chin. Sci. Bull. 47, 12, 1033-1036, DOI: 10.1360/02tb9232.

Yuan, Y., X. Huo, J. Ou, K. Zhang, Y. Chai, D. Wen, and R. Grenfell (2008a), Refining the Klobuchar ionospheric coefficients based on GPS observations, IEEE Trans. Aerosp. Electron. Syst. 44, 4, 1498-1510.

Yuan, Y., C.C. Tscherning, P. Knudsen, G. Xu, and J. Ou (2008b), The ionospheric eclipse factor method (IEFM) and its application to determining the ionospheric delay for GPS, J. Geodesy 82, 1, 1-8, DOI: 10.1007/s00190-0070152-2. 
Zakharenkova, I.E., Iu.V. Cherniak, A. Krankowski, and I.I. Shagimuratov (2015), Vertical TEC representation by IRI 2012 and IRI Plas models for European mid latitudes, J. Adv. Space Res. 55, 8, 2070-2076, DOI: 10.1016/j.asr. 2014.07.027.

Received 10 July 2015 Received in revised form 22 November 2015 Accepted 21 December 2015 